\title{
18
}

\section{Crowdfunding in the Cultural Industries}

\author{
Anders Rykkja, Natalia Maehle, Ziaul Haque Munim, \\ and Rotem Shneor
}

\section{Introduction}

Cultural production in general, and music in particular, has stood at the forefront of crowdfunding adoption (Moritz and Block 2016; Agrawal et al. 2014), with ArtistShare active from 2003 as a fan-funding platform for music projects being one of the first platforms ever established (Bannerman 2012). This trend is globally driven by challenges faced by

\section{A. Rykkja ( $\bowtie)$}

Inland Norway University of Applied Sciences, Hamar, Norway

e-mail: Anders.Rykkja@inn.no

N. Maehle

Western Norway University of Applied Sciences, Bergen, Norway

e-mail: Natalia.Mehle@hvl.no

Z. H. Munim

Faculty of Technology, Natural Sciences and Maritime Sciences, University of South-Eastern Norway, Horten, Norway

e-mail: Ziaul.H.Munim@usn.no

R. Shneor

School of Business and Law, University of Agder, Kristiansand, Norway e-mail: rotem.shneor@uia.no 
cultural organizations such as the cuts in public funding and increased competition for donors and sponsors (Boeuf et al. 2014; Papadimitriou 2017), as well as the advent of digitalization (Hesmondhalgh 2013; Nordgård 2018; Peltoniemi 2015). Both challenges are profoundly affecting the conditions and framework for creating, producing, distributing, and consuming cultural expressions.

Changes in traditional models for investments in cultural production, as well as structures and value chains, create alternative pathways and circumvention of traditional intermediaries (Peltoniemi 2015). For example, in the music sector, there is a shift away from a label-centred economy to an artist-centred economy (Tschmuck 2016), in which the artist holds more aesthetic freedom, and also bigger economic and management responsibilities. Thus, in times with increasing possibilities for self-production of artistic content, crowdfunding represents a pathway towards a more open and diverse sectoral structure, with the potential for realizing a broad spectre of cultural productions.

While a variety of types of crowdfunding models are available, crowdfunding in the cultural sector is predominantly of the reward-based type, mostly mirroring the presale of a product or service. A recent European report found that $88 \%$ of the estimated 75,000 campaigns launched by stakeholders in the cultural sector are reward-based (De Voldere and Zeqo 2017). In addition, crowd patronage (Swords 2017) has also been identified as a model allowing subscription-like payments to individuals to fund their ongoing occupation or career, which is often regarded as of particular relevance for artists in line with historical tradition.

Despite the critical role played by artists as first adopters of crowdfunding, research dedicated to the role and impact of crowdfunding on stakeholders in the cultural sector remains limited. This is surprising as crowdfunding may have critical influence on the balance between the commercial and the non-commercial value, the popular and the alternative artistic expression, aesthetic practices both online and offline, as well as the very structure of cultural funding. Indeed some claim that the significance of crowdfunding is in that it 'shift mindsets and realities around organizational possibility, potentially reinforcing and extending, or even altering, the traditional organization of cultural production' (Bannerman 2012, p. 7). 
In this chapter we review earlier research on crowdfunding in the cultural sector, while highlighting key research themes and related studies. Next, we outline opportunities for future research development and suggest some implications for practice.

\section{Cultural Crowdfunding}

Cultural production refers to creation, production, distribution, and consumption of cultural products and services (Venkatesh and Meamber 2006). Cultural crowdfunding (hereafter 'CCF') refers to the use of crowdfunding for the financing of production, distribution, and consumption of cultural expressions. The distinctive aspects of CCF are anchored in the unique nature of the projects seeking funding. Such projects involve ideas and artistic expressions, which are often characterized as having higher experiential (Power 2002), symbolic (Throsby 2001), and aesthetic value (Hirsch 1972), as well as non-utilitarian nature (Lawrence and Phillips 2002).

Accordingly, originality may play a greater role in assessing market opportunities than utility, and emotional appeal may have greater impact on patterns of consumption than rational considerations. However, what constitutes originality and emotional appeal may differ significantly between individual consumers (Lampel et al. 2006), as it depends on individual taste, preference, and aesthetic opinions (Bourdieu 1984). Thus, neither the producers nor the consumers know ex-ante if the originality dimension of the cultural expression will be in line with the personal preferences of consumers (Kappel 2009).

Like crowdfunding in other sectors, CCF has multiple objectives and benefits that go beyond funding. A recent large-scale study of crowdfunding in the European cultural and creative sectors (De Voldere and Zeqo 2017) found that $80 \%$ of surveyed campaigners experienced their crowdfunding campaigns as serving purposes beyond finance, such as audience development, community engagement, skills development, promotion, and market research. Nevertheless, it can be argued that dependence on fans as well as a long tradition of patronage and subscription-based pre-selling have been important precursors of funding 
cultural projects well before the digital age, and to a greater extent than in other sectors.

Regardless of the objectives of a crowdfunding campaign, the cultural work itself may have both economic and cultural values to a greater or lesser extent. Hence, in order to define what constitutes a cultural project we use Throsby's concentric circles model of the cultural industries (Throsby 2008). Industries closer to the core have greater cultural than economic value, and the further away a sector is positioned from the core, the heavier is its focus on commercial and economic value. Consequently, in the inner circle, where cultural value is perceived as highest, we find the 'core' creative artistic activities such as literature, music, performing arts, and visual arts. Its surrounding layer includes other 'core' industries such as film, photography, museums, galleries, and libraries. The wider circle of cultural and creative industries includes heritage services, publishing and print media, television and radio, sound recording, as well as video and computer games. Finally, the last layer includes related industries with a heavy cultural component including advertising, architecture, design, and fashion.

Industry figures and statistics specific to CCF are limited. Nevertheless, some findings from a study of the European CCF industry (De Voldere and Zeqo 2017) are illustrative. This study revealed that between 2013 and 2016 there were 75,000 CCF campaigns raising a total of EUR 247 million. When broken into sub-industries, data showed the following distribution of campaigns: Film and Audiovisual (33\% of campaigns and $29 \%$ of transaction volume), Music (22\% of campaigns and $17 \%$ of transaction volume), Performing Arts (13\% of campaigns and 9\% of transaction volume), Design (11\% of campaigns and $15 \%$ of transaction volume), Visual Arts (10\% of campaigns and $6 \%$ of transaction volume), Literature and Press (8\% of campaigns and 13\% of transaction volume), Gaming ( $2 \%$ of campaigns and $5 \%$ of transaction volume), Architecture ( $2 \%$ of campaigns and $5 \%$ of transaction volume), and Heritage (less than $1 \%$ in terms of both number of campaigns and transaction volume).

The numerous campaigns and their public records reflect the complexity of CCF realities. For illustration purposes, one can highlight certain cases that have attracted attention from both academics and practitioners. First, in the music sector, musician, singer, and songwriter Amanda 
Palmer successfully and wholeheartedly embraced crowdfunding when raising USD 1.2 million on Kickstarter from close to 25,000 backers on Kickstarter in 2012. She continued her success via the Patreon platform grossing an additional USD 1.6 million by 2018 from some 15,000 patrons. The reasons behind this success are Palmer's investment in building a community of loyal fans, as well actively engaging with them both online via social media and offline in the physical world (Williams and Wilson 2016). In this respect, Palmer embraced a relationship with her fans by responding to their messages, empathizing with their stories, and talking about all of it in an authentic way on her own channels (Conditt 2019).

A different example from the music sector is the crowdfunding experience of Public Enemy, a highly successful million-selling hip-hop group. In 2009, the group launched their crowdfunding campaign on the platform Sellaband. The initial target of the campaign was USD 250,000, but upon reaching only $28 \%$ of the goal after two months, they had to lower the objective to USD 75,000 and relaunch the campaign in 2010. Eventually, by October 2010, they succeeded in raising USD 81,950 from 1453 contributors. In this case, the initial failure, despite the group's prominent position and established fanbase, can be explained by the lack of interaction between the group members and their followers, as well as the misalignment between their commercial interests and their followers' price sensitivity (Williams and Wilson 2016). The latter point can be exemplified by the fact that the group was charging USD 100 for two CDs or USD 250 for two CDs and a T-shirt, which may be perceived as either unfairly priced or outside financial capacities of many potential fans.

Other examples from the film industry present additional interesting insights. The following two successful crowdfunding efforts exhibited masterful mobilization of a fanbase, while resulting in different market outcomes at the end of the process.

On the one hand, there is Iron Sky, a Finnish-Austrian-Australian cult sci-fi movie franchise. The first movie Iron Sky premiered in 2012, with the follow-up Iron Sky: The Coming Race distributed to cinemas in 2019. Production and financing of both films relied on a combination of crowdsourcing, crowdfunding, and crowd investment. Iron Sky was partly 
co-created by a community of 2000 fans covering part of the costs by buying 'war bonds' at 50 euros. The fans also contributed to a variety of production tasks and duties including script and score writing, special effects, subtitling, and acting (Kirsner 2009), and even going to the length of setting up their own 'Wreck-a-movie' platform to facilitate participation (Tryon 2015). The funding of production of the sequel came via four different crowdfunding campaigns. Indiegogo hosted three of them, one for script development and promotion (EUR 166,652 from 3517 patrons), one for production (EUR 600,138 from 9408 patrons), and one for post-production (EUR 34,801 from 415 patrons) between July 2013 and November 2016. The fourth campaign on the equity platform Invesdor raised 268,500 euros from 421 investors, with a target set at 50,000-150,000 euros.

Here despite impressive engagement of followers in co-creative participation and fundraising, the case highlights the fragility of crowdfunding in the face of inability to live up to promises. This leads to an imbalance in the relations between promoter and patrons, as fans may feel that their efforts as prosumers and co-creators are taken for granted. While it is difficult to predict the reception of a cultural production financially ex-ante, Iron Sky was well off the mark. The second movie only grossed USD 400,000 out of a production cost of some USD 21 million (IMDB 2019), leading the production company to file for bankruptcy. And while that may have been a possibility all along, inadequate communication with supporters throughout the process might have further tarnished the professional reputation of the people behind the campaign.

On the other hand, the crowdfunding success of the Veronica Mars movie initiative was supported by over 90,000 fans of the Veronica Mars TV show, which aired from 2004 to 2007. The fans contributing over USD 5.7 million to make the film a reality, almost tripling the original target amount of USD 2 million (Booth 2015). Despite much controversy based on criticism of fan exploitation for funding rich studios, the people behind the campaign needed the money as a symbol of their fandom to convince Warner Bros. that the movie was viable, and hence get them engaged in its production (Chin et al. 2014). Eventually, the film grossed USD 3.5 million internationally and made an additional USD 5.3 million from Blu-ray and DVD sales in the US (The Numbers 2020). 
Parallel to CCF practice, as illustrated above, CCF research has emerged to better understand its antecedents, characteristics, patterns, and success while accounting for related complexities and sub-sectoral particularities.

\section{A Review of Research on Cultural Crowdfunding}

Research into crowdfunding in the cultural sector has grown considerably in recent years. A bibliometric analysis conducted by Rykkja et al. (2019) of 84 studies on crowdfunding in a wide variety of cultural industries has identified five core themes. These themes address aspects of value creation, roles of the fan community, drivers of campaign success, journalism-specific insights, and reflections on crowdfunding experiences. In this section we present each theme while providing highlights from its key studies.

First, in terms of value creation, several studies have examined how CCF creates value beyond funding. Most studies in this context focus on aspects of value co-creation (Payne et al. 2008) through interaction between campaign creators and the public of prospective fans and backers. Here, a study by Quero et al. (2017) identifies the following seven forms of value co-creation when analysing cases of CCF in Spain: coideation, co-design, co-evaluation of ideas, co-financing, co-testing, colaunch, and co-consumption. Nucciarelli et al. (2017) provide similar insights claiming that co-creative interactions between gamers and developers via crowdfunding platforms may offer new value chain configurations involving the user community. More specifically, in the music industry, evidence suggests that crowdfunding is affecting the major labels in terms of adaptation of their marketing model to become more creative, resilient, and artist-friendly while tapping into opportunities of user-centred innovation (Gamble et al. 2017). In addition, when consumption is intertwined with social missions and ideology, crowdfunding may serve as a tool to accomplish social and political ends such as creating communities of support, attracting media attention, and building a reputation for an independent voice, as demonstrated in the analysis of the 
use of crowdfunding for production of documentary films in Turkey (Koçer 2015).

Second, another strand of studies focuses on the types and roles of fan communities in supporting CCF. Here, some research identifies the criticality of mobilization of existing fan communities for funding cultural productions of established artists (Booth 2015), as well as the importance of investing in building up fan communities as part of the crowdfunding process for supporting new artists (Galuszka and Brzozowska 2016). Members in such fan communities may either take a patron's stance allowing artists to create 'authentic' rather than 'commercially driven' artistic production (Swords 2017) or a prosumer-investor stance influencing the design and production processes (José Planells 2015). In both cases, the support of both affirmational (non-creatively engaged) and transformational (co-creatively engaged) fans has symbolic value that goes beyond their actual financial contributions, as it boosts the artistic credibility of a creator, while enhancing her perceived economic power and value vis-à-vis industry decision-makers and funders (NavarGill 2018).

The third research stream examines the drivers of successful CCF campaigning in particular and can be seen as a sector-specific subset of a wider research stream into crowdfunding success in general (e.g. Shneor and Vik 2020). Here, since the majority of CCF has employed the reward crowdfunding model (De Voldere and Zeqo 2017), related research has mostly identified success indicators that are relevant for reward crowdfunding campaigns. Some of the most prevalent findings across studies seem to suggest that success of CCF campaigns is positively associated with (1) project quality signals captured by campaign text length, as well as media richness in terms of the number of images, videos, and graphics included in the campaign (e.g. Bi et al. 2017; Cha 2017); (2) the mobilization and extension of social capital as evident through different levels of social media interaction and spread of e-word-of-mouth in terms of 'likes', comments, and shares (e.g. Bao and Huang 2017; Bi et al. 2017); and (3) the campaigners' human capital in terms of prior professional experience (e.g. Cha 2017; Steigenberger 2017) and prior crowdfunding experience (e.g. Boeuf et al. 2014). 
The fourth theme identified includes a series of articles addressing unique aspects of journalism crowdfunding. Journalism may represent a unique context for crowdfunding for several reasons. First, journalism uses donation rather than reward crowdfunding as its main model of choice, in line with the concept of creating public goods rather than products and services for individual consumption. Second, the reliance on crowdfunding creates unique ethical challenges where journalists need to balance their journalistic work between objectivism and agenda advocacy (Hunter 2015) and setting boundaries to co-creation (Porlezza and Splendore 2016). Such problems are potentially conflated by the fact that donors seem to be more motivated by fun and family relations than by ideals of freedom, altruism, and community engagement (Jian and Shin 2015), and therefore tend to support stories focusing on practical guidance for daily living rather than stories on public affairs such as those covering cultural diversity or government and politics (Jian and Usher 2014; Ladson and Lee 2017).

Finally, the fifth group is a collection of case studies about crowdfunding experiences with respect to two sectoral contexts-film producers and GLAM (Galleries, Libraries, Archives, and Museums) organizations. Common across them is the reflection on failure in addition to success, the importance of tapping the right niche crowds, and the development of communities around projects with a sense of belonging. The studies examining film production reflect on experiences of limited success or outright failure, and criticize the extent to which crowdfunding democratizes cultural productions, as it tends to follow capitalistic considerations of consumer value and demand rather than sociocultural considerations (e.g. Papadimitriou 2017; Sheppard 2017). The studies examining GLAM organizations also reflect on experiences of limited success and failure; however, they conclude with pragmatic advice on strong outreach efforts and constant communication with the community (e.g. Bushong et al. 2018; Riley-Huff et al. 2016).

Beyond these five main thematic clusters, one may identify a few smaller groups of studies around some additional themes of interest. For example, two studies examine to what extent crowd evaluations of campaigns differ from those of experts in the context of the performing arts (Mollick and Nanda 2015) and in the context of the music recording 
industry (Bernard and Gazel 2018). Both studies find that, overall, the crowd and experts tend to agree on project quality; however, experts may be more supportive of innovative projects, while the crowd tends to support less risky and 'mainstream' campaigns.

Another group of studies investigates the implications of CCF at times of cuts and changes in public funding of the arts. The authors with critical approach perceive crowdfunding either as a solution in which crowd volunteerism makes up for the reduction in traditional funding (Perry and Beale 2015) or as a form of political argumentation for defunding public intervention (Brabham 2016). Others, such as Binimelis (2016), highlight that government agencies along with private finance intermediaries (e.g. banks and companies) are still struggling to adapt their strategies to these market developments and shifts.

\section{Opportunities for Future Research on Cultural Crowdfunding}

In addition to the themes discussed above, one can also identify potential new themes that future research may follow. While multiple opportunities exist, in the current section we outline three specific areas for further investigation.

First, few studies have investigated barriers and drivers for artists' use and adoption of crowdfunding. The earlier research in this area is limited and has mostly focused on the barriers. Thorley (2012) suggest that crowdfunding force artists to perform unfamiliar downstream activities such as sales and marketing, and hence may not benefit creators who could make important cultural contributions but have neither the inclination to expose themselves nor an already existing community of admirers (Davidson and Poor 2015). More research is necessary for understanding drivers of crowdfunding adoption. Here, creation of a typology of CCF fundraisers based on their fit with CCF practice requirements may be helpful. Moreover, further studies are invited to address the strategies for mitigating crowdfunding adoption barriers for each type of fundraiser, as well as to evaluate the extent to which current and future platform services cater to their needs. 
An additional theme for future research may relate to artists' choice of platforms. The limited available research has focused on the choice between international and local platforms. For example, De Voldere and Zeqo (2017) show that although Europe was home to some 600 crowdfunding platforms, almost half of European CCF campaigns (47\%) between 2013 and 2017 were hosted on global US-based platform. In an attempt to explain such choice, a recent study by Rykkja et al. (2020) analysing CCF campaigns from the Nordic countries has found that cultural productions with a higher degree of production complexity and those characterized as incorporating composite motives are more likely to use an international platform, while projects with high degree of cultural affinity opt for using local platforms. Additionally, they show that the higher the funding goal, the more fundraisers are likely to opt for using international platforms rather than local ones. Such work may be replicated in different contexts, as well as extended to the choice among different types of platforms such as generalist (e.g. Kickstarter, Indiegogo) versus sector-specific platforms (e.g. ArtFund, DigVentures, Unbound).

Furthermore, since ample evidence exists that countries differ in terms of geographical spread of cultural activity, cultural sector specializations, consumption patterns, and cultural policies (e.g. Bekhuis et al. 2012; Boix et al. 2014; van Hek and Kraaykamp 2013), as well as in terms of crowdfunding volumes, model composition, and platform availability (Ziegler et al. 2020), it is surprising that cross-country comparisons of CCF remain mostly absent. Future studies are encouraged to examine how national level characteristics such as availability of public funding, availability of public-private match-funding schemes, nationalistic tendencies, agglomeration of cultural sectors, regulatory environment, freedom indicators, as well as cultural dimensions may all impact CCF in different environments. Such efforts may help identify macro-level indicators that support or inhibit the development of CFF in different country contexts, while shifting the focus away from micro-level analyses to macro-level ones. 


\section{Conclusions}

Digitalization has had a pronounced impact on the cultural industries, from reconfigurations of traditional value chains to the opening of new channels for financing and co-production of cultural projects. Unlike in many other industries, the cultural industries have a long history of project financing via patronage and public fundraising initiatives (Swords 2017). Hence, it is not surprising that cultural production has stood at the forefront of adopting crowdfunding as a modern digital format for financing its projects. Nevertheless, CCF seems to rely heavily on noninvestment models of crowdfunding (De Voldere and Zeqo 2017; Rykkja et al. 2020) and has not yet ventured into investment finance. Hence, the use of this channel is expected to further evolve and expand. While CCF represents an emerging source of funding, it does not yet substitute traditional funding sources in most cases (Laycock 2016; Navar-Gill 2018; Papadimitriou 2017).

The study of crowdfunding in the specific context of the cultural industries is of interest, as it challenges project creators to strike a balance between the economic and socio-cultural values, as well as between independent expression and co-creation with others. This chapter contributes to the field by identifying key themes in the earlier research related to value creation, fan communities, campaign success drivers, experiences and failures, as well as journalism-specific insights. Besides, we highlight opportunities for future research such as further investigations of drivers and barriers of crowdfunding adoption by artists, platform choices, and macro-level comparative analyses of market conditions that are more or less conducive to successful CCF development and growth.

Furthermore, this chapter suggests some implications for practitioners. First, insights emerging from the research on success and failure of CCF campaigns may inform future fundraisers in their efforts in campaign development, help platforms design their services for campaigners, as well as provide educational content to consultants and trainers advising prospective fundraisers. Here, some of the most prevalent factors in this regard is the importance of social capital build up and mobilization in the form of fan and follower communities offering members opportunities 
for enhancing their sense of belonging and co-creation. Also, the use of quality materials in campaign information as well as signalling fundraiser credibility and experience, are of critical importance for enhancing success.

Second, beyond a general need for more crowdfunding-oriented education, there is a specific need for programmes tailored for artists and individuals working in the cultural industries. Such programmes should cover fundamental crowdfunding themes (e.g. crowdfunding models, campaign development, platform choice) in addition to specialized units for CCF. Here, units should cover themes that enhance the sense of selfefficacy and skills in marketing and sales. In addition, programmes should incorporate reflective discussion on dilemmas involving the balance between commercial and non-commercial value creation, independent creation versus co-creation with others, as well as authenticity versus popular demand.

Acknowledgements The work for this publication was supported by the Norwegian Art Council grant number 17/2254, under its 'Digital kultur, estetiske praksiser' programme.

\section{References}

Agrawal, A., Catalini, C., \& Goldfarb, A. (2014). Some Simple Economics of Crowdfunding. NBER Innovation Policy \& the Economy (University of Chicago Press), 14(1), 63-97.

Bannerman, S. (2012). Crowdfunding Culture. Wi: Journal of Mobile Culture, $6(4), 1-23$.

Bao, Z., \& Huang, T. (2017). External Supports in Reward-based Crowdfunding Campaigns: A Comparative Study Focused on Cultural and Creative Projects. Online Information Review, 41(5), 626-642.

Bekhuis, H., Meuleman, R., \& Lubbers, M. (2012). Globalization and Support for National Cultural Protectionism from a Cross-national Perspective. European Sociological Review, 29(5), 1040-1052.

Bernard, A., \& Gazel, M. (2018). La place de la foule dans le financementde projets musicaux: les financeurs participatifs et l'industrie financent-ils les 
mêmes projets ? In F. Moreau \& Y. Nicolas (Eds.), Financement participatif: une voie d'avenir pour la culture? Paris: Ministère de la Culture.

Bi, S., Liu, Z., \& Usman, K. (2017). The Influence of Online Information on Investing Decisions of Reward-based Crowdfunding. Journal of Business Research, 71, 10-18.

Binimelis, M. A. (2016). The Crowdfunding Discourses: Balance and Tensions around Audiovisual Democratisation. Ic-Revista Cientifica De Informacion $Y$ Comunicacion, 13, 10-18.

Boeuf, B., Darveau, J., \& Legoux, R. (2014). Financing Creativity: Crowdfunding as a New Approach for Theatre Projects. International Journal of Arts Management, 16(3), 33-48.

Boix, R., Capone, F., De Propris, L., et al. (2014). Comparing Creative Industries in Europe. European Urban and Regional Studies, 23(4), 935-940.

Booth, P. (2015). Crowdfunding: A Spimatic Application of Digital Fandom. New Media \& Society, 17(2), 149-166.

Bourdieu, P. (1984). Distinction: A Social Critique of the Judgement of Taste. Cambridge: MA, Harvard University Press.

Brabham, D. C. (2016). How Crowdfunding Discourse Threatens Public Arts. New Media \& Society, 19(7), 983-999.

Bushong, S., Cleveland, S., \& Cox, C. (2018). Crowdfunding for Academic Libraries: Indiana Jones Meets Polka. The Journal of Academic Librarianship, 44(2), 313-318.

Cha, J. (2017). Crowdfunding for Video Games: Factors that Influence the Success of and Capital Pledged for Campaigns. International Journal on Media Management, 19(3), 240-259.

Chin, B., Jones, B., McNutt, M., et al. (2014). Veronica Mars Kickstarter and Crowd Funding. Retrieved February 8, 2020, from https://doi.org/10.3983/ twc.2014.0519.

Conditt, J. (2019). The Crowdfunded Cult of Amanda Palmer. Retrieved February 8, 2020, from https://www.engadget.com/2019/12/13/ amanda-palmer-patreon-kickstarter-social-media/.

Davidson, R., \& Poor, N. (2015). The Barriers Facing Artists' Use of Crowdfunding Platforms: Personality, Emotional Labor, and Going to the Well One Too Many Times. New Media \& Society, 17(2), 289-307.

De Voldere, I., \& Zeqo, K. (2017). Crowdfunding: Reshaping the Crowd's Engagement in Culture. Brussels: European Commission. 
Galuszka, P., \& Brzozowska, B. (2016). Early Career Artists and the Exchange of Gifts on a Crowdfunding Platform AU-Galuszka, Patryk. Continuum, 30(6), 744-753.

Gamble, J. R., Brennan, M., \& McAdam, R. (2017). A Rewarding Experience? Exploring How Crowdfunding is Affecting Music Industry Business Models. Journal of Business Research, 70, 25-36.

Hesmondhalgh, D. (2013). The Cultural Industries. London: Sage.

Hirsch, P. M. (1972). Processing Fads and Fashions: An Organization-set Analysis of Cultural Industry Systems. American Journal of Sociology, 77(4), 639-659.

Hunter, A. (2015). Crowdfunding Independent and Freelance Journalism: Negotiating Journalistic Norms of Autonomy and Objectivity. New Media \& Society, 17(2), 272-288.

IMDB. (2019). Iron Sky: The Coming Race (2019) [Online]. Retrieved February 8, 2020, from https://www.imdb.com/title/tt3038708/.

Jian, L., \& Shin, J. (2015). Motivations Behind Donors' Contributions to Crowdfunded Journalism. Mass Communication and Society, 18(2), 165-185. Jian, L., \& Usher, N. (2014). Crowd-Funded Journalism. Journal of ComputerMediated Communication, 19(2), 155-170.

José Planells, A. (2015). Video Games and the Crowdfunding Ideology: From the Gamer-buyer to the Prosumer-Investor. Journal of Consumer Culture, 17(3), 620-638.

Kappel, T. (2009). Ex ante Crowdfunding and the Recording Industry: A Model for the US 29 Loy. Loyola of Los Angeles Entertainment Law Review, 29(3), 375-385.

Kirsner, S. (2009). Fans, Friends and Followers: Building an Audience and a Creative Career in the Digital Age. CreateSpace Independent Publishing Platform.

Koçer, S. (2015). Social Business in Online Financing: Crowdfunding Narratives of Independent Documentary Producers in Turkey. New Media \& Society, $17(2), 231-248$.

Ladson, N., \& Lee, A. M. (2017). Persuading to Pay: Exploring the What and Why in Crowdfunded Journalism. International Journal on Media Management, 19(2), 144-163.

Lampel, J., Shamsie, J., \& Lant, T. K. (2006). The Business of Culture: Strategic Perspectives on Entertainment and Media. Mahwah, NJ: Lawrence Erlbaum Associates. 
Lawrence, T. B., \& Phillips, N. (2002). Understanding Cultural Industries. Journal of Management Inquiry, 11(4), 430-441.

Laycock, R. A. (2016). The Audience's Worth: Crowdfunding as a Source of Film Finance. Metro Magazine: Media \& Education Magazine, 188, 112-117. Mollick, E. \& Nanda, R. (2015). Wisdom or Madness? Comparing Crowds with Expert Evaluation in Funding the Arts, August 26. Retrieved from http://papers.ssrn.com/sol3/papers.cfm?abstract_id=2443114.

Moritz, A., \& Block, J. H. (2016). Crowdfunding: A Literature Review and Research Directions. In D. Bruntje \& O. Gajda (Eds.), Crowdfunding in Europe: State of the Art in Theory and Practice. London: Springer.

Navar-Gill, A. (2018). Fandom as Symbolic Patronage: Expanding Understanding of Fan Relationships with Industry through the Veronica Mars Kickstarter Campaign. Popular Communication, 16(3), 211-224.

Nordgård, D. (2018). The Music Business and Digital Impacts: Innovations and Disruptions in the Music Industries. Switzerland, Springer: Cham.

Nucciarelli, A., Li, F., Fernandes, K. J., et al. (2017). From Value Chains to Technological Platforms: The Effects of Crowdfunding in the Digital Game Industry. Journal of Business Research, 78, 341-352.

Papadimitriou, L. (2017). Transitions in the Periphery: Funding Film Production in Greece Since the Financial Crisis. International Journal on Media Management, 19(2), 164-181.

Payne, A. F., Storbacka, K., \& Frow, P. (2008). Managing the Co-creation of Value. Journal of the Academy of Marketing Science, 36(1), 83-96.

Peltoniemi, M. (2015). Cultural Industries: Product-Market Characteristics, Management Challenges and Industry Dynamics. International Journal of Management Reviews, 17(1), 41-68.

Perry, S., \& Beale, N. (2015). The Social Web and Archaeology's Restructuring: Impact, Exploitation, Disciplinary Change. Open Archaeology, 1(1), 153-165. Porlezza, C., \& Splendore, S. (2016). Accountability and Transparency of Entrepreneurial Journalism. Journalism Practice, 10(2), 196-216.

Power, D. (2002). "Cultural Industries" in Sweden: An Assessment of their Place in the Swedish Economy. Economic Geography, 78(2), 103-127.

Quero, M. J., Ventura, R., \& Kelleher, C. (2017). Value-in-Context in Crowdfunding Ecosystems: How Context Frames Value Co-creation. Service Business, 11(2), 405-425.

Riley-Huff, D. A., Herrera, K., Ivey, S., et al. (2016). Crowdfunding in Libraries, Archives and Museums. The Bottom Line, 29(2), 67-85. 
Rykkja, A., Munim, Z. H., \& Bonet, L. (2020). Varieties of Cultural Crowdfunding: The Relationship between Cultural Production Types and Platform. Baltic Journal of Management, 15(2), from https://doi.org/10.1108/ BJM-03-2019-0091

Rykkja, A., Munim, Z. H., Maehle, N., et al. (2019). Cultural CrowdfundingWhat Do We Know? In 17th Interdisciplinary European Conference on Entrepreneurship Research (IECER), Utrecht, Netherlands.

Sheppard, S. N. (2017). I Love Cinema: Black Film and Speculative Practice in the Era of Online Crowdfunding. Film Quarterly, 71(2), 25-31.

Shneor, R., \& Vik, A. A. (2020). Crowdfunding Success: A Systematic Literature Review 2010-2017. Baltic Journal of Management, 15(2), 149-182.

Steigenberger, N. (2017). Why Supporters Contribute to Reward-based Crowdfunding. International Journal of Entrepreneurial Behavior \& Research, 23(2), 336-353.

Swords, J. (2017). Crowd-Patronage-Intermediaries, Geographies and Relationships in Patronage Networks. Poetics, 64, 63-73.

The Numbers. (2020). Veronica Mars (2014) [Online]. Nash Information Services, LLC. Retrieved February 8, 2020, from https://www.the-numbers. $\mathrm{com} / \mathrm{movie} /$ Veronica-Mars\#tab=video-sales.

Thorley, M. (2012). An Audience in the Studio-The Effect of the Artistshare Fan-Funding Platform on Creation, Performance, Recording and Production. Journal on the Art of Record Production, 7, 1-29.

Throsby, D. (2001). Economics and Culture. Cambridge: Cambridge University Press.

Throsby, D. (2008). The Concentric Circles Model of the Cultural Industries. Cultural Trends, 17(3), 147-164.

Tryon, C. (2015). Iron Sky's War Bonds: Cult SF Cinema and Crowdsourcing. In J. P. Telotte \& G. Duchovnay (Eds.), Science Fiction Double Feature: The Science Fiction Film as Cult Text. Liverpool: Liverpool University Press.

Tschmuck, P. (2016). From Record Selling to Cultural Entrepreneurship: The Music Economy in the Digital Paradigm Shift. In P. Wikström \& R. DeFillippi (Eds.), Business Innovation and Disruption in the Music Industry. Cheltenham, UK: Edward Elgar.

van Hek, M., \& Kraaykamp, G. (2013). Cultural Consumption Across Countries: A Multi-level Analysis of Social Inequality in Highbrow Culture in Europe. Poetics, 41(4), 323-341.

Venkatesh, A., \& Meamber, L. A. (2006). Arts and Aesthetics: Marketing and Cultural Production. Marketing Theory, 6(1), 11-39. 
Williams, J. A., \& Wilson, R. (2016). Music and Crowdfunded Websites: Digital Patronage and Artist-fan Interactivity. In S. Whiteley \& S. Rambarran (Eds.), The Oxford Handbook of Music and Virtuality. Oxford: Oxford University Press.

Ziegler, T., Shneor, R., Wenzlaff, K., et al. (2020). The Global Alternative Finance Benchmarking Report. Cambridge, UK: Cambridge Centre for Alternative Finance.

Open Access This chapter is licensed under the terms of the Creative Commons Attribution 4.0 International License (http://creativecommons.org/licenses/ by/4.0/), which permits use, sharing, adaptation, distribution and reproduction in any medium or format, as long as you give appropriate credit to the original author(s) and the source, provide a link to the Creative Commons licence and indicate if changes were made.

The images or other third party material in this chapter are included in the chapter's Creative Commons licence, unless indicated otherwise in a credit line to the material. If material is not included in the chapter's Creative Commons licence and your intended use is not permitted by statutory regulation or exceeds the permitted use, you will need to obtain permission directly from the copyright holder.

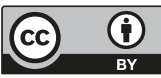

